\title{
As relações entre o governo do estado e a nascente imprensa apartidária no Rio Grande do Sul da Primeira República
}

Leandro José BRIXIUS ${ }^{1}$

Resumo:

O estado do Rio Grande do Sul foi governado por mais de 30 anos, no período da chamada Primeira República, por representantes do Partido Republicano Riograndense (PRR). Nessa época, a imprensa tinha como principal característica a vinculação de jornais aos partidos políticos, mas uma nova organização na área de comunicação começava a se estruturar: os veículos apartidários, com modo de gestão capitalista e características informativas e de imparcialidade. O artigo recupera fatos da relação entre o jornal Correio do Povo, representante dessa nova imprensa, com o governo do estado, para analisar a maneira como ela se construiu e apontar hipóteses a respeito da estratégia adotada por ambas as forças.

Palavras-chave: Partido Republicano Riograndense; imprensa; governo do Rio Grande do Sul; Correio do Povo.

\section{Relations between the state government and the nascent non- partisan press in Rio Grande do Sul of the First Republic}

\begin{abstract}
:
The state of Rio Grande do Sul was governed for over 30 years, during the First Republic, by representatives of the Riograndense Republican Party (PRR). At that time, the press was sponsored by political parties, but a new organization in the communication is beginning to be structure: non-partisan vehicles, with capitalist mode of management and informative and impartial features. The article recovers facts of the relationship between the newspaper Correio do Povo, representative of this new press, and the state government, to analyze the way it relationship was built and to hypothesize about the strategy adopted by both forces.
\end{abstract}

Keywords: Riograndense Republican Party; press; government of Rio Grande do Sul, Correio do Povo.

\section{Relaciones entre el gobierno del estado y la naciente prensa imparcial en Rio Grande do Sul durante la Primera República}

Resumen:

El estado de Rio Grande do Sul fue gobernado durante más de 30 años, durante el período de la denominada Primera República, por representantes del Partido Republicano Riograndense (PRR). En ese momento, la prensa tenía como principal característica la vinculación de los periódicos a los partidos políticos, pero se empezó a gestar una nueva organización en el área de la comunicación: vehículos imparciales, con un modo de gestión capitalista y características informativas e imparciales. El artículo recupera hechos de la relación entre el diario Correio do Povo, representante de esta nueva prensa, con el gobierno estatal, para analizar la forma en que fue construido y señalar hipótesis sobre la estrategia adoptada por ambas fuerzas.

Palabras clave: Partido Republicano Riograndense; prensa, gobierno de Rio Grande do Sul, Correio do Povo.

\footnotetext{
${ }^{1}$ Mestre em Ciências da Comunicação, pela Universidade do Vale do Rio dos Sinos (Unisinos), jornalista (Universidade Federal do Rio Grande do Sul), licenciando em História na Universidade Federal do Rio Grande do Sul (UFRGS).E-mail: leandrobrixius@gmail.com
} 
- Vou começar o quanto antes uma campanha pela imprensa contra o Trindade. Já tenho o nome para o meu jornal: A Farpa. Que parece?

Um próprio vindo da cidade trouxe um pacote de jornais, que Rodrigo abriu sofregamente. Destruiu sem ler os números de A Voz da Serra - que outra coisa não eram senão o eco desagradável da voz servil do rábula Amintas, a cantar loas ao Trindade, ao mal. Hermes ao "glorioso Partido Republicano" - e deitou-se na rede, deliciado, com um maço de exemplares do Correio do Povo. Leu-os metodicamente, começando pelo número mais atrasado, que era o de 5 de janeiro, e concentrou-se nas notícias políticas.

Erico Verissimo

Os trechos da epígrafe, extraídos de O Tempo e o Vento, obra-prima de Erico Verissimo (2004), mostram a relevância da imprensa para o discurso político no Rio Grande do Sul do começo do século XX. No primeiro excerto, o jovem médico recém-formado Rodrigo Terra Cambará, de volta à terra natal, Santa Fé, conta ao irmão, Toríbio, os planos que tem no início de 1910: fundar um jornal para atacar seu oponente, o intendente Titi Trindade. No segundo, o narrador descreve o prazer com o qual Rodrigo, de férias na estância do Angico, recebe exemplares do Correio do Povo, na época já com 15 anos, consolidando-se na imprensa gaúcha como voz isolada no nascente jornalismo apartidário, e o desdém dispensado ao A Voz da Serra, o jornal local que defende seu adversário.

Nas duas décadas finais do século XIX, o Rio Grande do Sul vivenciou mais um período conturbado de sua história, com disputas políticas que desembocaram nas armas. Em 1889, com a Proclamação da República, o Partido Republicano Riograndense (PRR) assumiu o poder estadual, onde permaneceria até 1930, comandando com as mãos de ferro de Júlio de Castilhos e de Borges de Medeiros, que governou por 25 anos.

Único meio de comunicação social existente na época, o jornal era um espaço importante para a disputa política, marcada essencialmente pelo confronto do PRR contra o Partido Federalista (PF), sucessor do Partido Liberal (PL) de Gaspar Silveira Martins, que comandara o estado no período imperial. Cada uma das forças políticas tinha seus próprios jornais e a imprensa como um todo era vinculada a um lado ou a outro. A exceção era o Correio do Povo, fundado em 1895 com a proposta de ser imparcial, focado em notícias, sem 
compromisso com correntes político-partidárias.

Neste artigo, será analisada a relação que se desenhou entre o governo do PRR e o jornalismo informativo e sem vinculação partidária, e não mais opinativo, que surge com o Correio.

\section{A chegada dos republicanos ao poder}

O grupo político dominante no Rio Grande do Sul do período imperial era liderado pelo liberal Gaspar Martins. O PL controlava a Guarda Nacional e a maioria dos municípios. Diferentemente de outras regiões do país, os republicanos não tiveram ampla adesão entre os gaúchos. No momento da Proclamação da República, em 15 de novembro de 1889, os liberais estavam fortes na província - os estancieiros gaúchos, base do PL, não tiveram grande impacto com a abolição da escravatura visto que a mão de obra escrava não era o principal suporte da atividade econômica e, por isso, não romperam com a Monarquia após 1888. Os gasparistas foram surpreendidos pelo golpe militar que depôs D. Pedro II. De uma hora para outra, os republicanos, grupo minoritário, viram-se na chefia do agora estado do Rio Grande do Sul. ${ }^{2}$

Essa troca de mãos do comando local não ocorreu de maneira tranquila. Segundo Félix (1987), houve adesão à República, mas não ao PRR. O partido republicano tinha maior presença entre a elite estancieira da região serrana do Planalto Médio, mas não penetrava entre os tradicionais estancieiros da Campanha e da Fronteira Oeste. O governo autoritário e centralizador de Júlio Castilhos desencadeou ódio e ressentimentos. A Constituição de 1891, elaborada pelo próprio presidente do estado sob inspiração positivista, tornava o Poder Executivo mais forte com a autorização para uso de decretos com valor de lei e relegava ao Poder Legislativo apenas a aprovação do orçamento. Segundo Félix (1987, p. 54), o

[...] projeto político republicano caracterizou-se por ser de cunho conservador autoritário, devido à preeminência da filosofia política de Júlio de Castilhos. Ela manifestou-se na ação frente aos municípios, visando desmontar a antiga máquina administrativa (e eleitoral) como forma de impor a "nova ordem". O PRR, embora minoritário, chegara à República perfeitamente estruturado e coeso, sob a liderança férrea do carismático Júlio de Castilhos, encarnando os ideais da República autoritária de inspiração positivista. Em contraposição, o gasparismo constituía-se na tendência republicana liberal, sob a arregimentação do Partido Federalista.

\footnotetext{
${ }^{2}$ A contextualização histórica do período é fundamentada em estudos de Félix (1987; 1995a; 1995b), Axt (2004) e Pesavento $(1983 ; 1996)$.
} 
A insatisfação entre os coronéis gaúchos teve seu ápice com a ruptura do "pacto imperial": os estancieiros defendiam a fronteira brasileira e o Império fazia vistas grossas ao contrabando que ocorria na região. O governo republicano extinguiu taxas alfandegárias privilegiadas e impôs o combate efetivo às transações comerciais ilegais na divisa com Uruguai e Argentina. Houve reação armada do grupo liberal, que além de alijado do poder, agora tinha perdas econômicas. Como ressalta Félix (1987, p. 55),

[...] os ressentimentos da elite tradicional, "afrontada" pelos novos quadros e ferida nos seus interesses, foram fatores mobilizadores para a luta. $\mathrm{O}$ objetivo era o esmagamento do castilhismo pelo que ele representava de opressão e perda econômica. Esses aspectos não podem ser dissociados.

Os gasparistas, agora alinhados no PF, tiveram a adesão de dissidentes do PRR, que não aceitavam a orientação ditatorial de Castilhos. A Revolução Federalista eclodiu em 1893, desenrolou-se ao longo de dois anos e "foi com certeza a mais séria das contestações enfrentadas pela recém-proclamada República brasileira" (PESAVENTO, 1983, p. 7). Para Félix (1987, p. 53), duas razões foram determinantes: "a diferença de projeto político presidencialismo x parlamentarismo - e a questão do poder local - autonomia de ação local frente ao Estado". Como quem ganhou foi Júlio de Castilhos, as relações entre o poder local, representado pelos coronéis, a maioria deles derrotados, e o poder estadual foram redefinidas. A também chamada Revolução da Degola deixou estimados 10 mil mortos e "contribuiu para a acentuada radicalização política que o Rio Grande do Sul experimentou nos 40 anos da República Velha que se seguiram”(PESAVENTO, 1983, p. 9).

Com o castilhismo legitimado pela revolução, a polarização política tornou-se ainda maior, com a consolidação do poder centralizado na figura do presidente. A burguesia agrária, representada pelos estancieiros da metade norte, desbancou a aristocracia rural da metade sul, emergindo juntamente com uma classe média formada por funcionários públicos e pequenos proprietários urbanos e rurais. $\mathrm{O}$ aparelho do estado passou por reestruturação, nova forma de relação do Executivo estadual com o poder local, o que não significou o abandono do poder pelos coronéis. Eles logo foram cooptados pelo castilhismo, especialmente sob Borges de Medeiros, que passa a governar a partir de 1898. Surge o coronelismo de modelo borgista. ${ }^{3}$

\footnotetext{
${ }^{3}$ Para Axt (2004, p. 8), "o Rio Grande do Sul também integrou aquilo a que se chamou de sistema coronelista de poder", mas, devido a especificidades, "o longo período de domínio de Júlio de Castilhos e Borges de Medeiros sobre o Estado não pode ser tratado como um bloco homogêneo, devido às inúmeras descontinuidades e conjunturas pontuais". Segundo Félix (1987), as características do coronelismo gaúcho são tradição militar da fronteira (atividade pecuária) e positivismo, adaptado pelo castilhismo-borgismo. Essas duas ideias centrais são desdobradas em quatro procedimentos explicativos: formação militar e violenta da ocupação da província;
} 
A imprensa como agente político

A consolidação do PRR no poder não passou somente por armas ou por negociações e troca de favores com coronéis locais. Desde antes mesmo da Proclamação da República, e da consequente chegada ao governo do estado, os líderes desse movimento tinham clareza de que era preciso um canal para disseminar as ideias republicanas, ainda que não de maneira massiva, dados os altos índices de analfabetismo, mas que atingisse a elite eleitora e com influência político-econômica. Então, “em 1883, no primeiro congresso realizado, tratou-se da necessidade de criação de um jornal partidário que melhor difundisse as novas ideias. Em 1884, surgia $A$ Federação, ${ }^{4}$ jornal que se tornou órgão oficial do PRR, tendo por redator Júlio de Castilhos" (PESAVENTO, 1983, p. 52). O discurso legitimador da ordem castilhista visava a persuadir, convencer os leitores, em uma prática de jornalismo opinativo, não informativo, constituído como espaço de militância político-partidária. Segundo Félix (1995a, p. 183),

A produção simbólica, decorrente do "efeito das palavras" teve na palavra escrita impressa um papel de extrema importância na segunda metade do séc. XIX e primeiras décadas do séc. XX, na América Latina como um todo e, especialmente, no RS. A imprensa tornou-se um espaço privilegiado de exercício de militância política, tanto nos jornais da 'grande imprensa' quanto da "pequena imprensa". Ao trabalharem com doutrinas e ideias, estabeleciam uma luta nos bastidores e nas páginas dos jornais e periódicos, em geral, percebida pelo tom forte do vocabulário usado, pelas expressões agressivas ou laudatórias, criando-se uma "nova noção de factualidade". Os editoriais constituíram-se tribuna política onde, muitas vezes, buscava-se universalizar o particular e particularizar o universal.

A prática não era exclusiva dos republicanos, já que os federalistas contavam com $A$ Reforma ${ }^{5}$ O Maragato e outros títulos. "Nenhum jornal deixava de ostentar publicamente a defesa de algum interesse político ou preceito filosófico”, como explica Galvani (1994, p. 46). Segundo Hohlfeldt e Rausch (2007), A Federação é considerada o primeiro jornal doutrinário do país, referência em razão de sua coerência e vigor de doutrinação. Era diário, exceto aos

predomínio da pecuária, com menor estratificação social e mais facilidade para coronéis cooptarem votos; proximidade com o Prata, que desenvolveu um "tipo peculiar de caudilho"; e a doutrina positivista.

${ }^{4}$ Conforme Rüdiger (1993), no auge do regime, na década de 1910, A Federação chegou a imprimir 10 mil exemplares, com reformas gráficas e editoriais que deixaram a publicação mais moderna. Na década de 1920 , começou a se descaracterizar e reduzir a tiragem. Foi extinta em 1937, por ato oficial do Estado Novo.

${ }^{5}$ A Reforma, do Partido Liberal, surgiu em 1869. Gaspar Silveira Martins foi seu principal diretor. Chegou a imprimir 20 mil exemplares na época da República Velha. Entre 1892 e 1896, ficou fechada em razão da "pressão policial movida pelo regime castilhista". Quando foi retomada, não tinha mais a mesma força. Em 1912, foi suspensa, "por ordem dos poderes superiores de federalismo rio-grandense" (RÜDIGER, 1993, p. 30). 
domingos, e circulava à tarde, com quatro páginas em tamanho standard. Para além de reportar os fatos, o jornal, como órgão político-partidário, criava acontecimentos:

Os artigos, sempre redigidos por Castilhos, apresentam caráter pedagógico. Logo, a técnica teria presença marcante no conteúdo do jornal republicano, dentro do estilo publicístico do jornalismo político-partidário, que encontrava seu ápice na propaganda política daquele período. (HOHLFELDT; RAUSCH, 2007, p.13).

Para Rüdiger (1993, p. 31), “A Federação resumiu de fato o modelo do jornalismo político-partidário vigente no Rio Grande do Sul até o Estado Novo". Um relato de João Neves da Fontoura, publicado em um livro de memórias pela Editora do Globo em 1956 e transcrito pelo autor, descreve que $A$ Federação não era um jornal como os demais, "feitos todas as tardes no tumulto da improvisação" (RÜDIGER, 1993, p. 32). Seu conteúdo era elaborado com "cuidados religiosos, liturgicamente, de caso pensado" (RÜDIGER, 1993, p. 32). Antes de ser impresso, o artigo principal era submetido ao chefe do PRR, que o devolvia com observações, tanto negativas quanto positivas:

Castilhos, orador medíocre, mas especialista da pena, criou novas concepções jornalísticas, principalmente o conceito prático de que a imprensa não precisa limitar-se a registrar os acontecimentos políticos, pois que pode modificar seu curso. [...] O jornalismo não é uma força passiva, embora partidariamente engajada, do processo de formação da opinião pública, mas um fator ativo de modelagem pública da própria opinião. (RÜDIGER, 1993, p. 31).

Nessa tarefa de "modificar o curso dos acontecimentos", A Federação acabava no centro de disputas com outros jornais sob acusação de falsear os fatos. Félix (1995b), ao analisar duas publicações de língua alemã que circulavam no período da Revolução Federalista (1893-95), Deutsches Volksblatt (DV) e Deutsche Post (DP), relata como se dava a relação com outros veículos. DV, de viés católico e inclinação castilhista, embora sem explicitar sua vinculação, acusa $A$ Federação de publicar notícias falsas sobre a revolução, assim como relata a proibição a $O$ Mercantil de publicar informações alarmantes. No período da disputa bélica, o jornal alemão também refere a empastelamento de jornais, prisões de jornalistas e censura a textos. O DP, de vinculação luterana, posição perceptível, segundo a autora, pelo viés das publicações, também questiona as notícias do jornal do PRR, conforme trecho transcrito por Félix (1995b, p. 160): “As notícias de 'Federação' nem sempre são confiáveis. O 'Rio Grande' tem razão quando questiona [...]. Não, não acreditamos em paz. 
Acreditamos muito mais em um futuro nebuloso".

Conforme Félix (1998, p. 146), tanto A Federação quanto os demais jornais do PRR espalhados pelas cidades do interior gaúcho usaram "recursos da construção mítica no processo de heroicização de Júlio de Castilhos". O presidente do estado e chefe do partido era apresentado como "herói salvador" e "protetor". A doença de Castilhos, mesmo grave, não foi citada em A Federação. Dois dias depois do falecimento, ocorrido em 24 de outubro de 1903, o artigo principal do jornal tratou da morte do político, iniciando, segundo Félix, a construção do mito. "Frases como: 'Sim, vivamos d'Elle, de seu passado, de seu nome' ou 'A veneração do Rio Grande, dos republicanos [...] não se limitará às manifestações platônicas do sentimento', nos mostram a veneração religiosa que começa a se processar-se" (FELIX, 1998, p. 147)

O sucessor, Borges de Medeiros, é o responsável por "guardar e venerar a sacrossanta memória de Júlio de Castilhos", transcreveu Félix (1998, p. 148) do editorial de 11 de novembro de 1903. Para Félix (1993, p. 52), esse tipo de jornalismo opinativo era baseado na “crença no poder mágico das palavras como sacralizadoras do político, capazes de, por si só, provocarem mudanças na sociedade. Enquanto elementos revolucionários, seriam propagadoras de novas ideias e agentes de transformação do status quo".

O jornalismo político-partidário surgiu em um processo no qual, segundo Rüdiger (1993, p. 24), a

[...] classe política transformou a imprensa em agente orgânico da vida partidária. Após a Revolução, não foram poucos os tipógrafos que conquistaram cargos políticos, de modo que logo a propriedade de um jornal se tornou meio de ascensão política. A consolidação dos partidos políticos que se esboçou nessa época paulatinamente institucionalizou essa prática.

$\mathrm{Na}$ época das campanhas eleitorais, o número de publicações multiplicava-se pelo interior do Rio Grande do Sul, como bem pretendia fazer o personagem Rodrigo Cambará citado na epígrafe. O jornal era o principal meio de propaganda e difusão de ideais políticos. A censura policial direta a folhas da oposição era regra nos primeiros anos do governo do PRR, com o fechamento das publicações e a prisão dos responsáveis. "Durante o governicho, quando a dissidência republicana momentaneamente tomou o poder, a administração baixou um decreto proibindo o anonimato em qualquer artigo publicado na imprensa, o que gerou uma onda generalizada de protestos", relata Rüdiger (1993 p. 34). Essa medida foi 
amplamente defendida por $A$ Federação, que só não teve pleno êxito em razão da deterioração do "governicho". Na fronteira, jornais tinham por hábito transferir suas operações para o outro lado, fixando-se no Uruguai ou na Argentina, escapando, assim, das forças oficiais e de censura, pois "para garantir o silêncio do adversário político, o principal meio empregado na época era a perseguição policial aos jornalistas e a destruição das oficinas onde se publicavam os jornais" (RÜDIGER, 1993, p. 36).

Mesmo que vinculados a partidos, esses jornais começavam a apresentar um tipo de racionalidade no funcionamento das redações e, conscientes da necessidade de informar de maneira geral, também publicavam relatos de ocorrências do cotidiano.

Até mesmo os jornais claramente partidários, como A Federação, constituem-se enquanto empresas e necessitam de capital a ser integrado por seus apoiadores, bem como de atrativos para seus leitores, atrativos que devem ir além daqueles vinculados diretamente ao partido. (HOHLFELDT, 2006, p. 7).

\section{O jornalismo apartidário e sua relação com o poder}

O jornalismo político-partidário entrou em crise no Rio Grande do Sul a partir do final da primeira década do século XX por diversos motivos, principalmente econômicos, mas um dos fatores preponderantes foi a ascensão do Correio do Povo.

A formação, senão de uma sociedade, pelo menos de uma mentalidade burguesa, favorecia a diversificação das concepções jornalísticas vigentes, propondo a supremacia de novos valores como a veracidade noticiosa e a imparcialidade editorial, que na realidade contribuíam para a expansão do público potencial de cada periódico ao rejeitarem o compromisso políticopartidário do jornalismo dominante à época. Em consequência disso, verifica-se a manifestação cada vez mais comum do princípio da neutralidade nos novos jornais, que visam com isso não somente em subtrair às conveniências partidárias, mas promover o "interesse geral da sociedade" (JORNAL DO COMMERCIO, Porto Alegre, 21 jan. 1885 apud RUDIGER, 1993, p. 46).

Os veículos de imprensa focados em notícias e informação começaram a ter impulso maior quando se estruturaram como verdadeiras empresas, com o lucro como sua finalidade, ocupando o lugar das antigas associações entre tipógrafos, jornalistas e comerciantes. Ainda segundo Rüdiger (1993, p. 54), “o Correio do Povo foi o primeiro jornal a realmente tomar esse rumo, que possibilitou à imprensa noticiosa vencer seus obstáculos e constituir um novo regime jornalístico no Rio Grande do Sul”. 
Em $1^{\text {o }}$ de outubro de 1895 , chegou às ruas o jornal fundado por Caldas Júnior. ${ }^{6} \mathrm{O}$ artigo na capa da primeira edição trazia os princípios que norteariam a publicação: seu caráter noticioso, literário e comercial, com independência, não servindo a nenhuma facção. Para Rüdiger (1993, p. 58), havia, após os três anos de Revolução Federalista que cingiu o estado, um "clima favorável para o surgimento de um jornal não-comprometido com a política, mas somente com a causa pública". Ainda segundo o autor, o fundador "descobriu que o caráter político do jornalismo não precisava ser explícito, que havia uma mutação em curso nas necessidades do público e do próprio espectro deste público, estabelecendo novos termos para a concorrência no mercado dos jornais" (RÜDIGER, 1993, p. 60).

Rüdiger afirma que, apesar dessa postura de independência, o Correio nunca foi um jornal apolítico. Hohlfeldt e Rausch (2007, p. 17) acrescentam que, “embora sem engajamento partidário, os jornais não deixarão de expor uma opinião a respeito de fatos políticos e sociais que implicam no contexto em que estão inseridos". Por isso, a chegada desse novo veículo não passou sem impacto nos concorrentes e no governo. Na época, Porto Alegre possuía meia dezena de jornais em circulação - tratavam-se de edições modestas, de quatro páginas, geralmente, e que além dos jornais partidários, contava com a imprensa ligada à imigração italiana e, principalmente, alemã - e a proposta do Correio rompia com a prática vigente, como descreve Dillenburg (1997, p. 21):

Não foi sem motivo, portanto, que o surgimento do Correio do Povo, por obra de Caldas Júnior, com sua proposta de um jornalismo independente, alcançou tanta expectativa e, mesmo, incredulidade entre os gaúchos. Bastaram, no entanto, poucas edições do novo jornal para que os leitores percebessem que a proposta do Correio do Povo, de não ser vinculado a nenhuma facção partidária, era para valer.

Logo nos primeiros meses, o Correio do Povo alcançou relevância entre os leitores, não só nas rodas de conversa, mas também com anúncios e assinaturas, conforme Galvani (1994). Desde o início, a postura de independência proclamada por Caldas Júnior foi tratada como de oposição pelo PRR - no típico posicionamento "se não está comigo, está contra mim". Os ataques de A Federação ao Correio eram frequentes, mas a política de Caldas era evitar entrar em polêmicas, o que muitas vezes não aconteceu.

\footnotetext{
${ }^{6}$ Francisco Antônio Vieira Caldas Júnior nasceu em Sergipe, em 1868, filho de um magistrado, e mudou-se aos quatro anos para Santo Antônio da Patrulha, no Rio Grande do Sul, seguindo ainda criança para Porto Alegre. Começou sua carreira jornalística no jornal A Reforma, depois transferiu-se para o Jornal do Comércio, de onde saiu para fundar o Correio do Povo. O pai, desembargador na atual Florianópolis, foi fuzilado em Santa Catarina durante a Revolução Federalista junto com quase duas centenas de pessoas (GALVANI, 1994).
} 
Em 10 de janeiro de 1896, se deu o primeiro embate com A Federação, segundo a pesquisa realizada por Galvani (1994). Com o pseudônimo Tenório, Caldas Júnior escreveu um editorial com críticas ao jornal oficial. Era uma resposta a referências anteriores feitas pela publicação do PRR. Em 1897, a compra de uma nova máquina possibilitou a tiragem de 2 mil exemplares por hora, demonstrando o crescimento do Correio. As relações com A Federação seguiam tensas em 1898, na troca do comando do governo de Castilhos para Borges, em 25 de janeiro. Caldas Júnior dedicou um editorial a quem deixava o poder, no qual elogiava “efusivamente o 'jornalista emérito, o polemista energético e vibrante, o político perspicaz e inteligente", mas também o acusava de "'manter uma férrea política partidária, que provocara profundos ódios no Rio Grande do Sul'” (Apud DILLENBURG, 1997, p. 29). A posse de Borges teve primeira página e grande cobertura. Em um artigo, o Correio "procurava encerrar de vez a pendenga escrevendo que o seu objetivo era 'ser justo, nem propendendo para um lado, nem para o outro"” (GALVANI, 1994, p. 69).

Mas na mesma época houve novo embate. O Correio criticou um aumento de impostos realizado pelo intendente José Montaury. No dia 10 de janeiro, relacionando ao fato, A Federação insinuou que os textos do Correio não eram escritos por jornalistas, mas por políticos da oposição, e que Caldas queria um emprego nas repartições. A resposta veio no dia 12, com a exaltação da defesa dos direitos do povo e o desafio ao adversário, para que provasse o que falava. No dia 13, A Federação respondeu e, no dia seguinte, veio o Correio novamente. Seguiu-se nova sequência de trocas de acusações. A polêmica só se encerrou em 23 de janeiro, com o Correio afirmando que só respondera após anos de provocações.

Quando Júlio de Castilhos morreu, em 1903, o necrológio publicado pelo Correio foi exaltado, o que colocou uma trégua na troca de farpas, segundo Galvani (1994). Dois anos depois, a viúva de Castilhos suicidou-se e recebeu tratamento de primeira-dama por ordem de Caldas (GALVANI, 1994).

Um caso curioso foi o embate nas páginas do Correio em torno da vacinação. O positivismo, inspiração filosófica do governo do PRR, era contrário à aplicação de vacinas e o jornal, favorável. Em 29 de agosto de 1905, essa posição ficou explícita, como escreve Galvani (1994, p. 124):

O Correio teve a independência e a ousadia - significava um novo enfrentamento com o governo de Borges de Medeiros, herança castilhista e portanto positivista - de registrar numa entrevista de primeira página com o 
diretor da Higiene, Dr. Protásio Alves, aliás também capaz de um gesto de independência e altivez:

Achas - perguntou o repórter do Correio do Povo - que a vacina, como alguns positivistas propalam, enfraquece o organismo humano?

- Absolutamente não! - respondeu o Dr. Protásio Alves.

Caldas Júnior vibrou com a matéria que o Daniel Job escrevera, até porque lembrava-lhe sempre os preceitos instituídos no primeiro editorial, dez anos passados.

Não há registro do autor se houve alguma retaliação de $A$ Federação, do PRR ou do governo. Em 1910, quando o Correio do Povo se mudou para novo endereço, em prédio próprio e mais amplo, houve registros na concorrência, como era praxe na época, com elogios, inclusive, publicados em A Federação. O jornal do PRR escreveu: "O Correio é hoje o jornal que possui melhor instalação no Estado", segundo transcrição de Galvani (1994, p. 148). Em $1^{\text {o }}$ de janeiro de 1912 , o Correio devolveu a gentileza, registrando a compra de novos equipamentos por A Federação, destacando que permitiriam maior capacidade de impressão.

Na gestão de Carlos Barbosa, entre 1908 e 1913, há menos registros de altercações entre o Correio e o poder estadual, seja com o próprio chefe do Executivo ou seu "porta-voz", A Federação. Caldas Júnior foi, inclusive, convidado pelo governo a fazer parte da comissão que trataria da criação de um instituto de belas artes, fato que teve destaque no Correio, conforme Galvani (1994). O autor também relata a saída de Carlos Barbosa do governo, descrevendo que, "no dia 23 daquele mês (janeiro de 1913), a redação engalanou-se para receber a visita do presidente do Estado que deixava o cargo: Dr. Carlos Barbosa" (GALVANI, 1994, p. 173, grifo meu).

Na longa gestão de Borges de Medeiros, que se estendeu até o início de 1928, a relação de troca de farpas não se modificou, tendo, inclusive, se acirrado após a morte de Caldas Júnior, em 9 de abril de 1913, aponta Galvani (1994) ao citar exemplos disso. O presidente do estado não compareceu ao enterro, nem mesmo às missas de $7^{\circ}$ e $30^{\circ}$ dia de falecimento. Na inauguração da herma do jornalista, Borges fez-se representar mais uma vez pelo capitão Cássio Brum Pereira. ${ }^{7}$ Ao analisar o Correio no período de Borges, Balbinot (2008) aponta que havia um alinhamento do jornal mais com a oposição do que com a situação. A relação entre o Correio e A Federação era tensa:

\footnotetext{
${ }^{7}$ Borges também se fez representar pelo capitão na visita do ex-presidente americano Theodore Roosevelt a Porto Alegre e não foi às homenagens a Olavo Bilac em 1916, quando o poeta visitava a capital, ambas atividades citadas por Galvani (1994) a partir de registros no Correio do Povo, o que pode demonstrar apenas que o governador não era afeito a eventos sociais, e não uma implicância com o jornal.
} 


\begin{abstract}
A Federação, mais governista do que nunca, não perdoava uma linha sequer, um único adjetivo, uma referência por menor que fosse que o Correio fizesse que de certa forma atingisse o governo estadual. E foi assim que, a propósito da mudança da sede do Tesouro do Estado - que acabou não se concretizando - e de uma descoberta do Correio de que o Frigorífico Armour conseguiria livrar de impostos a entrada de 30 mil cabeças de gado, provenientes do Uruguai, e mais duas ou três leves referências a enganos administrativos, estourou uma polêmica naquela final de dezembro de 1921 (GALVANI, 1994, p. 231).
\end{abstract}

Em 25 de janeiro de 1928, Getúlio Vargas assumiu o governo do Rio Grande do Sul e o Correio do Povo logo se associou "ao programa do futuro candidato gaúcho ao Catete", inclusive com propaganda no alto da primeira página: "Para os supremos postos da magistratura brasileira no próximo quadriênio: Getúlio Vargas e João Pessoa", segundo Galvani (1994, p. 257). "Essa propaganda política derruba a antiga tese da imparcialidade, se ela já não tivesse sofrido, ao longo do tempo, tantos arranhões", completa o autor (GALVANI, 1994, p. 258).

Fernando Caldas, filho do fundador e diretor do jornal, entrou de corpo e alma - e de bolso, já que o dinheiro do Correio apoiava a Aliança Liberal - na campanha de Getúlio, o que gerou críticas de concorrentes, segundo Galvani (1994). Na véspera da eleição de $1^{\circ}$ de março de 1930, a primeira página era toda dedicada a Getúlio Vargas e João Pessoa, que acabaram por perder a disputa. Na sequência, o Correio apoiou a Revolução de 30 e mancheteou em 5 de outubro: "Rio Grande, de pé pelo Brasil, não poderás falhar ao teu destino", como relata Galvani (1994, p. 287).

\title{
Considerações finais
}

Nos 35 anos de existência do Correio do Povo durante a Primeira República, não há relato de censura ${ }^{8}$ por posicionamento político ou atos como empastelamentos e prisões de jornalistas do jornal. No entanto, foram frequentes os enfrentamentos com o poder estadual. A publicação de notícias críticas à gestão e a atos desagradava o governo. A bibliografia consultada para este artigo mostra que as respostas não vinham diretamente do presidente do estado, mas pelo jornal do PRR, A Federação.

Duas hipóteses podem explicar essa relação pelo lado do governo. Borges de Medeiros, presidente do Rio Grande do Sul na maior parte da Primeira República, teria se

\footnotetext{
${ }^{8}$ O único caso de censura no período ocorreu em 1918, quando a gripe espanhola assolava o Rio Grande do Sul. Os jornais, incluindo o Correio do Povo, foram proibidos pelo governo do estado de publicar informações sobre a epidemia sob alegação de que estavam disseminando pânico. Os espaços nos quais seriam publicadas notícias da moléstia ficavam em branco, indicando ao leitor a censura (GALVANI, 1994).
} 
valido de um canal eficiente e relevante na sociedade - A Federação - e assim evitado se envolver pessoalmente em polêmicas. Além disso, essa postura pode estar vinculada com a estratégia de Borges de manter um mínimo de oposição em atividade. Segundo Axt (2004, p. 12), "não era conveniente, por sua vez, extinguir completamente a oposição ao borgismo, já que a ameaça de um inimigo comum ativo preservava melhor a unidade interna do PRR". O partido era profundamente cindido por facções internas, o que tornava impossível formar um bloco inabalável, mas isso exigia a existência de um comando forte - ele, o próprio Borges. Em ambos os casos, seria preciso aprofundar a pesquisa com análise de documentação, correspondências e relatos para avançar nas conclusões.

A manutenção de um discurso de imparcialidade por parte do Correio também pode explicar o motivo pelo qual Borges suportou a existência de um jornal cada vez mais influente a criticá-lo. Quando o Correio assumiu posicionamento favorável a Getúlio Vargas e à Revolução de 30, a situação teve alterações (mesmo que tenham ocorrido para além do período deste artigo, os fatos auxiliam na compreensão). Fiel a Getúlio, o jornal criticou a aproximação de Flores da Cunha com o Partido Republicano Liberal. A reação foi forte e inédita até então, segundo Dillenburg (1997). O Correio foi atacado por A Federação e jornais pertencentes à família de Flores, redatores foram presos e deportados e a rede ferroviária foi proibida de transportar o jornal. Prefeitos eram orientados a devolver assinaturas e encerrar colaborações com a publicação.

O Correio do Povo, amparado nos princípios expressos por Caldas Júnior na primeira edição do jornal, respondia que a dor de Flores da Cunha era não conseguir mandar no jornal. Como na ficção de Erico Verissimo, ter um jornal forte era importante na luta política e a enfraquecida $A$ Federação não cumpria mais o papel de porta-voz doutrinadora que desempenhou por décadas na Primeira República.

\section{Referências}

AXT, Gunter. Júlio de Castilhos e Borges de Medeiros: a prática política no RS. Cadernos IHU Ideias, São Leopoldo, ano 2, n. 14, 2004. Disponível em: http://www.ihu.unisinos.br/images/stories/cadernos/ideias/014cadernosihuideias.pdf. Acesso em: 20 dez. 2021.

BALBINOT, Jonas. Relações de poder: Getúlio Vargas e Borges de Medeiros (1922-1928). 2008. Dissertação (Mestrado em História) - Programa de Pós-Graduação em História, Universidade de Passo Fundo, Passo Fundo, 2008. Disponível em: 
http://tede.upf.br/jspui/handle/tede/122. Acesso em: 20 dez. 2021.

DILlenburG, Sérgio. Correio do Povo: história e memórias. Passo Fundo: Ediupf, 1997.

FÉLIX, Loiva Otero. Coronelismo, borgismo e cooptação política. Porto Alegre: Mercado Aberto, 1987.

FÉLIX, Loiva Otero. Pica-paus e maragatos no discurso da imprensa castilhista. In: POSSAMAI, Zita (org.). Revolução Federalista de 1893. Porto Alegre: Secretaria Municipal da Cultura, 1993.

FÉLIX, Loiva Otero. Imprensa, revolução e discurso: a construção de categorias. In: FÉLIX, Loiva Otero; RAMBO, Arthur Blásio (org.). Revolução Federalista e os teuto-brasileiros. São Leopoldo: Unisinos; Porto Alegre: Editora da Universidade/UFRGS, 1995a. p. 179-185.

FÉLIX, Loiva Otero. Religião, imprensa e Revolução Federalista. In: FÉLIX, Loiva Otero e RAMBO, Arthur Blásio (org.). Revolução Federalista e os teuto-brasileiros. São Leopoldo: Unisinos; Porto Alegre: Editora da Universidade/UFRGS, 1995b. p. 147-163.

FÉLIX, Loiva Otero. A fabricação do carisma: a construção mítica-heróica na memória republicana gaúcha. In: FÉLIX, Loiva Otero; ELMIR, Cláudio P. (org.). Mitos e heróis: construção de imaginários. Porto Alegre: Editora da Universidade/UFRGS, 1998.

GALVANI, Walter. Um século de poder: os bastidores da Caldas Júnior. Porto Alegre: Mercado Aberto, 1994.

HOHLFELDT, Antonio. A imprensa sul-rio-grandense entre 1870 e 1930. E-Compós, Brasília, dez. 2006. Disponível em: https://www.e-compos.org.br/e-compos/article/view/118. Acesso em: 20 dez. 2021.

HOHLFELDT, Antonio; RAUSCH, Fábio. Jornal A Federação, o difusor da propaganda republicana gaúcha. Signos, Lajeado, ano 28, n. 1, p. 7-21, 2007.

PESAVENTO, Sandra. A Revolução Federalista. São Paulo: Editora Brasiliense, 1983.

PESAVENTO, Sandra. Borges de Medeiros. 2. ed. Porto Alegre: IEL, 1996.

RÜDIGER, Francisco. Tendências do jornalismo. Porto Alegre: Editora da Universidade/UFRGS, 1993.

VERISSIMO, Erico. O tempo e o vento: o retrato. São Paulo: Companhia das Letras, 2004 (1951). v. 1.

Submetido em: 07.08.2019.

Aprovado em: 07.12.2021. 